\title{
Olhares psicossociais para a prática docente: elaboração de uma estratégia investigativa
}

\author{
Psychosocial perspectives for teaching practice: the \\ development of a research strategy
}

Miradas psicosociales para la práctica docente: elaboración de una estrategia de investigación

\author{
Adelina Novaes ida \\ ÉRIKA KULESSA DE SOUZA (iDb \\ PaUlo Afranio SANT'ANNA $\mathbb{D i D}^{c}$
}

\section{Resumo}

A análise sistemática das produções vinculadas aos projetos abrigados pelo Centro Internacional de Estudos em Representações Sociais e Subjetividade - Educação (CIERSed) da Fundação Carlos Chagas apontou para a necessidade de desenvolvimento de uma pesquisa que buscasse uma compreensão contextualizada sobre representações sociais associadas à ação de professores. O Projeto "Olhares psicossociais para a prática docente" foi construído com o intuito de ampliar a possibilidade de estabelecer conexões entre representações sociais e práticas educacionais a partir da consideração de distintas formas de linguagem. Sua abordagem etnográfica e sua configuração em rede levaram à elaboração de um protocolo, consensuado com os 44 grupos de pesquisa associados ao Centro. O processo e o resultado da criação desse documento são apresentados no

\footnotetext{
a Fundação Carlos Chagas (FCC), São Paulo, SP, Brasil. Pós-doutorado em Psicologia Social, e-mail: anovaes@fcc.org.br

b Fundação Carlos Chagas (FCC), São Paulo, SP, Brasil. Mestrado em Educação, e-mail: erikaksouza@gmail.com

c Universidade Federal dos Vales de Jequitinhonha e Mucuri (UFVJM), Diamantina, MG, Brasil. Pósdoutorado em Educação, e-mail: pa.anna1@gmail.com
} 
artigo, que visou ainda discutir os desafios da realização de um estudo multissituado e de se ambicionar uma generalização analítica com a conclusão do Projeto.

Palavras-chave: Representações sociais. Práticas docentes. Etnografia. Generalização analítica.

\begin{abstract}
The systematic analysis of the productions related to the projects sheltered by the International Center for Studies on Social Representations and Subjectivity - Education (CIERS-ed) of the Carlos Chagas Foundation pointed to the need to develop a research that sought a contextualized understanding of social representations associated with the action of teachers. The Project "Psychosocial perspectives for teaching practice" was elaborated with the aim of expanding the possibility of establishing connections between social representations of educational objects and teachers' practices, from the consideration of different forms of language. Its ethnographic approach and its network configuration led to the elaboration of a protocol, consensuated with the 44 research groups associated to the Center. The process and the result of the creation of this document are presented in the article, which also aimed at discussing the challenges of carrying out a multi-site study and of aspiring to a analytical generalization with the conclusion of the Project.
\end{abstract}

Keywords: Social representations. Teaching practices. Ethnography. Analytical generalization.

\title{
Resumen
}

El análisis sistemático de las producciones relacionadas con los proyectos abrigados por el Centro Internacional de Estudios en Representaciones Sociales y Subjetividad - Educación (CIERS-ed) de la Fundación Carlos Chagas señaló la necesidad de desarrollar una investigación que buscara una comprensión contextualizada de las representaciones sociales asociadas a la acción de maestros. El proyecto "Miradas psicosociales para la práctica docente" se elaboró con la intención de ampliar la posibilidad de establecer conexiones entre representaciones sociales de objetos educativos y prácticas de maestros, a partir de la consideración de las diferentes formas de lenguaje. Su enfoque etnográfico y su configuración en red llevaron a la elaboración de un protocolo, consensuado con los 44 grupos de investigación asociados al Centro. El proceso y el resultado de la creación de este documento se presentan en el artículo, que también tenía como objetivo discutir los retos de llevar a cabo un estudio multisituado y de aspirar a una generalización analítica con la conclusión del Proyecto.

Palabras clave: Representaciones sociales. Prácticas de enseñanza. Etnografía. Generalización analítica. 


\section{Introdução}

Neste artigo buscamos compartilhar os esforços que empreendemos no processo de construção do protocolo de pesquisa do projeto "Olhares psicossociais para a prática docente"1. O estudo, conduzido pelo Centro Internacional de Estudos em Representações Sociais e Subjetividade - Educação (CIERS-ed), em parceria com a Cátedra UNESCO sobre Profissionalização Docente ${ }^{2}$ do Departamento de Pesquisas Educacionais da Fundação Carlos Chagas (FCC), congrega 44 grupos de pesquisa na investigação que busca oferecer uma pluralidade de informações contextualizadas sobre o trabalho docente, por meio de estudo psicossocial, de caráter etnográfico, amparado por multimétodos de coleta e análise.

Tendo em vista a complexidade do projeto e sua extensão no que concerne ao número de pesquisadores e instituições envolvidas, optamos por realizar um processo participativo por meio de reuniões técnicas e seminários formativos envolvendo os pesquisadores associados ao Centro e buscamos manter um diálogo contínuo com autores e pesquisadores que subsidiaram teoricamente a elaboração das estratégias metodológicas ${ }^{3}$.

O Projeto foi motivado pelas reflexões resultantes do balanço de uma década das produções desenvolvidas pelos grupos de pesquisa associados ao CIERS-ed (NOVAES; SOUSA; VILLAS BÔAS, 2019). O Centro, que foi criado em 2006, sob iniciativa de Serge Moscovici (Fondation Maison des Sciences de l'Homme, França), Denise Jodelet (École des Hautes Études en Sciences Sociales, França) e Clarilza Prado de Sousa (Fundação Carlos Chagas, Brasil), possui o objetivo de realizar investigações científicas no âmbito da educação por meio do estudo da teoria das representações sociais (TRS) em articulação com outros referenciais teórico-

\footnotetext{
${ }^{1}$ Disponível em: https://www.fcc.org.br/fcc/wp-content/uploads/2020/01/Protocolo.pdf.

${ }^{2}$ Coordenada por Lúcia Villas Bôas (Fundação Carlos Chagas e Universidade Cidade de São Paulo Brasil).

${ }^{3}$ Nosso especial agradecimento à Clarilza Prado de Sousa, fundadora e consultora do CIERS-ed (Pontifícia Universidade Católica de São Paulo e FCC - Brasil); Ruth Mercado Maldonado (Departamento de Investigaciones Educativas do Centro de Investigación y de Estudios Avanzados del Instituto Politécnico Nacional - México), Elba Siqueira de Sá Barretto (FCC), Angela Maria Martins (Universidade Cidade de São Paulo e FCC - Brasil), Maria da Conceição Passeggi (Universidade Federal do Rio Grande do Norte e Universidade Cidade de São Paulo - Brasil) e Ecleide Cunico Furlanetto (Universidade Cidade de São Paulo - Brasil).
} 
metodológicos de modo a analisar e refletir sobre os processos educacionais, bem como seus consequentes sociais.

Com início em 2014, o Projeto "Balanço das produções do CIERS-ed de 2006 a 2015: sistematizações e proposições para o campo da educação e das representações sociais" incluiu a organização e análise de 16 livros, 222 capítulos de livros e 399 artigos. O resultado do estudo evidenciou a prevalência de duas perspectivas que têm embasado as investigações do CIERS-ed desde sua criação: a perspectiva psicossocial das representações sociais e o trabalho docente.

As pesquisas descritas nessas produções apontaram para a importância de não reduzir a educação à TRS, ou vice-versa, e destacaram a necessidade de desenvolvimento de estudos que busquem oferecer informações contextualizadas para a construção de um campo que compreenda a possibilidade de explicação dos processos simbólicos da educação pela perspectiva da TRS, sem modificar o enfoque que caracteriza uma ação educativa.

Tais considerações conduziram à realização de reuniões técnicas com os grupos associados ao Centro para o delineamento dialogado da nova investigação em rede. O Projeto "Olhares psicossociais para a prática docente" abraça um desafio ainda maior do que aqueles anteriormente apresentados, visto que possui caráter etnográfico e multissituado, sendo realizado em variados contextos do Brasil. Esse processo resultou na elaboração do documento norteador do trabalho de campo, debatido nas páginas que seguem.

\section{Por que adotar uma abordagem etnográfica para o estudo das relações entre representações e práticas docentes?}

A análise das produções do CIERS-ed permitiu a identificação de um universo de investigações fundadas na TRS que recorrem aos discursos de profissionais da educação e educandos para compreender suas representações acerca de objetos educacionais. Tendo em conta a função de orientação de ações das representações sociais (JOVCHELOVITCH, 2011, p. 168), os estudos relacionam as representações identificadas nos discursos dos respondentes às práticas que elas orientariam. 
Nosso intuito com o Projeto "Olhares psicossociais para a prática docente" é ampliar a possibilidade de estabelecer conexões entre representações sociais e práticas, a partir da consideração de distintas formas de linguagem e in loco. Tal investimento buscou inspiração em estudos que articulam etnografia à TRS, com destaque ao trabalho pioneiro de Jodelet (2005) e aos que vêm sendo desenvolvidos por FloresPalácios (2014) e Serrano Oswald (2013).

Um projeto multissituado, de abordagem etnográfica, que articulasse TRS e educação não havia sido proposto até então. Tal fato pode decorrer de distintas razões: (a) congregar grupos, localizados em diferentes estados das distintas regiões brasileiras, em torno de um propósito de estudo comum requer a orquestração de espaços de diálogo e de construção coletiva; (b) encontros, sejam presenciais ou à distância, demandam tempo e a reunião de distintos fomentos (o financiamento da pesquisa matriz, os financiamentos das pesquisas de cada grupo); (c) estudos de caráter etnográfico exigem longo mergulho no campo e a produção de vasto material que, por sua vez, resulta em demandante processo sistematização e análise; (d) pesquisas de abordagem etnográfica não permitem generalizações estatísticas, a forma de generalização que pode ser pretendida é analítica, o que requer exaustivo aprofundamento dos pesquisadores na TRS.

Há ainda outro fator que merece destaque, que diz respeito precisamente à condução da investigação. Ainda que muitas pesquisas educacionais recorram à etnografia como parte de sua metodologia, autores demonstram certa preocupação quanto ao que seria um uso superficial do método etnográfico em tais estudos, ou uma visão da etnografia como mera técnica de coleta de dados em abordagens qualitativas (ANDRÉ, 2007). Para Oliveira (2013), muitas das autodenominadas pesquisas de "tipo etnográfico" ou de "cunho etnográfico" acabam por desvincular o método de sua teoria, ou seja, encaram a prática etnográfica como algo dissociado de conceitos antropológicos que são fundamentais para a própria constituição desse método de pesquisa.

O autor menciona, por outro lado, que há uma longa tradição de diálogo entre antropologia e educação, notadamente no campo dos estudos da infância e dos processos de socialização. Nesses trabalhos é possível observar a construção do objeto de pesquisa educacional a partir do olhar antropológico e da observação 
participante, ao mesmo tempo em que a prática etnográfica em ambientes educativos possibilita a construção de conhecimento antropológico na educação e a renovação das teorias antropológicas (OLIVEIRA, 2013).

A imersão do etnógrafo no ambiente estudado, sua convivência e interação prolongada com os sujeitos de pesquisa têm como finalidade construir as condições para uma aproximação às formas de pensar e de organizar a vida social do grupo investigado. O movimento almejado por Malinowski (2016a), de compreender o outro e sua visão de mundo a partir dessa imersão, da observação e participação nas atividades cotidianas e dos registros descritivos das práticas, transformaram o modo de estudar e compreender as diferenças. Ainda que o método tenha se distanciando de algumas premissas de seu precursor, por meio de intensas reflexões epistemológicas sobre a relação entre os sujeitos de pesquisa, a proposta de ir a campo para conhecer e compreender o outro a partir de seus próprios referenciais, afastando as explicações preconcebidas e estereótipos sobre suas práticas e saberes, continua sendo uma postura crucial para pesquisas em ciências humanas e sociais.

O registro descritivo proposto pela etnografia busca captar exaustiva e detalhadamente as situações para apreendê-las em suas relações com o todo complexo do universo cultural estudado. O olhar proporcionado pela proximidade construída entre pesquisador e pesquisados torna possível conhecer a lógica dos grupos observados, compreender sua visão de mundo e modo de vida. Esse movimento, por sua vez, possibilita ao pesquisador rever seus conhecimentos e os do grupo ao qual pertence, alargar sua própria visão de mundo, alcançar o objetivo final de todo esse processo ou, nas palavras de Malinowski, "transformar esse conhecimento em sabedoria" (MALINOWSKI, 2016b, p. 142).

O ambiente escolar é conhecido de todos aqueles que passaram pela educação regular. Temos sobre ele uma coleção de memórias, crenças, teorias, juízos e representações. Tal familiaridade com o ambiente pode tornar mais difícil a tarefa de observar o que acontece em sala de aula, o que reforça a importância de um trabalho conceitual prévio e paralelo ao trabalho de campo. Conforme Velho (1978), a familiaridade pode comprometer o trabalho do pesquisador se não for objeto de reflexão sistemática, pois estar acostumado com determinado ambiente e ter conhecimentos sobre o modo de interação entre os sujeitos conforme seus papéis 
sociais não significa compreender a lógica que permeia suas relações, pelo contrário, é um conhecimento comprometido por estereótipos, expectativas e pelas categorias de classificação a partir das quais fomos socializados.

Quando vamos à escola como pesquisadores, buscamos algo diferente daquilo que já sabemos. Por mais integrados que possamos sentir-nos no ambiente escolar, o pesquisador é sempre um estrangeiro e esta condição é característica do fazer etnográfico. Mesmo quando o pesquisador é também docente, se entramos na escola como pesquisadores, olhamos para aquele contexto com outra perspectiva e somos vistos de outro modo por professores, estudantes, gestores e funcionários. Em outros termos, o olhar etnográfico fortalece a postura de quem busca apreender e interpretar uma realidade que reconhece como sendo estranha a ele, ou seja, é um pressuposto que não conhecemos aspectos importantes do que acontece na escola, do que sabem os professores e da construção social da prática docente (MERCADO MALDONADO, 2002; 2019).

Por outro lado, a constante problematização da relação eu-outro no fazer etnográfico contribui para que o observador não se coloque na posição de avaliador ou aferidor da qualidade das interações que ali se desenvolvem. Isso porque a etnografia tem na alteridade um elemento central e articulador do processo reflexivo: ao admitir que olhamos para o outro a partir de nossas concepções, estabelecemos uma vigilância em relação ao etnocentrismo presente em nossas interpretações. Tratase de aproximar-se da realidade do outro para tentar compreendê-la, afastando prejulgamentos, mas trata-se também de reconhecer a si mesmo enquanto sujeito social naquelas interações.

Nesse sentido, o trabalho de campo não é considerado como uma etapa anterior dissociada do trabalho interpretativo. As teorias antropológicas e pesquisas etnográficas levam à compreensão de que ao produzir os registros estamos também interpretando, pois não nos despojamos nem de nossa formação cultural, nem de nossas questões de pesquisa quando vamos a campo. Significa dizer que o trabalho do pesquisador reside em refletir constantemente sobre como seus pressupostos estão implicados em sua inserção no campo, na interpretação que faz das situações observadas e reconhecer como tais interpretações aparecem em seus registros (VELHO, 1978; MERCADO MALDONADO, 2019). 
Um dos desafios de nossa pesquisa multissituada, em rede, é o de que no material produzido durante o trabalho de campo já existe um esforço inicial de interpretação e ordenação, que será posteriormente objeto de análise pormenorizada e teórica e reordenado como descrição etnográfica. Frequentemente, é nesse momento posterior que notamos as ausências, as lacunas e podemos perceber se as nossas ideias prévias nos levaram a desviar o olhar ou negligenciar fatos que pareceram triviais e que, no entanto, compõem a totalidade que almejamos alcançar e são essenciais para compreendê-la (MALINOWSKI, 2016b).

O compromisso com esse esforço de análise paralelamente ao trabalho de campo e a compreensão de que estamos influenciados por nossas concepções prévias contribuem para evitar ou diminuir tais problemas, o que demanda dos 44 grupos associados ao CIERS-ed frequentes reuniões entre participantes e aprofundamento no referencial teórico que nos congrega.

O caderno ou diário de campo que acompanha os pesquisadores em nosso caso é combinado a um documento, elaborado com o propósito de permitir a reunião do trabalho de todos os grupos, na busca de convergências entre todos e especificidades de cada contexto. O protocolo busca alertar para a necessidade de produção de informações, anotações, descrições e impressões a respeito da experiência do pesquisador em campo e para o registro de fatos e situações presenciadas e relatadas. Dessa forma, ele permitirá também tomar distância do campo para analisar o processo de desenvolvimento da pesquisa e para uma autoanálise do pesquisador sobre sua experiência.

Significa reconhecer que, por mais minuciosos que sejam os registros, o pesquisador faz escolhas sobre o que e como registrar, com quem conversar, o que indagar. A etnografia considera o material de campo como resultado do olhar do pesquisador e das situações provocadas por sua presença no ambiente estudado, e de modo algum como um registro neutro de informações "coletadas" em campo.

Essa é a perspectiva que assumimos quando nos propusemos combinar a etnografia ao estudo das narrativas de docentes e discentes, bem como com as narrativas produzidas pelos pesquisadores sobre os contextos escolares observados (NOVAES; PASSEGGI, 2020; ANDRADE; TEIBEL; ASSUNÇÃO, 2020, SEIDMANN, 2020; FURLANETTO, 2018). 
Buscamos ainda considerar os efeitos do observador sobre o observado e suas ações, uma vez que a presença do observador interfere na situação, mas não a torna menos real, nem diminui as possibilidades da investigação. Para que a situação de pesquisa não gere desconforto ao docente, a observação das aulas nos tem demandado a construção de um espaço de abertura para discutir as situações com os docentes, compartilhando com eles os objetivos da pesquisa e reconhecendo os saberes que são construídos em seu trabalho cotidiano. Quando os sujeitos envolvidos compreendem os pressupostos e a proposta da pesquisa, participar dela é também uma situação que provoca autorreflexão sobre as práticas cotidianas, o que pode ser muito proveitoso para docentes, na medida em que têm a oportunidade de discutir seu trabalho em sala de aula com um outro que também está disposto a discuti-la e compreendê-la.

Em outros termos, a etnografia tem nos oferecido a possibilidade de pensar o trabalho de campo como uma experiência mais ampla do que a coleta de dados, pois considera a vivência do pesquisador como parte do processo de pesquisa e de produção de conhecimento. $\mathrm{Na}$ intersubjetividade diferentes representações sociais são acionadas e ressignificadas. Nesse processo investigativo, discurso, representações e práticas são considerados simultaneamente.

Durante a experiência etnográfica, questões de pesquisa têm sido elaboradas e reelaboradas. Vamos a campo com determinados objetivos e problemas, mas precisamos estar atentos ao que o campo nos mostra acerca dos processos que observamos. Assim, as conversas e interações cotidianas na escola têm sido indispensáveis para o desenvolvimento do estudo, incluindo aquelas que dizem respeito à presença do observador. Em outros termos, as conversas informais que acontecem entre pesquisadores e pesquisados oferecem tanto ou mais elementos para a interpretação das situações quanto as entrevistas formais (MERCADO MALDONADO, 2019).

Essa abrangência do olhar etnográfico está relacionada à ideia de que é possível atingir uma visão holística por meio do trabalho rigoroso e minucioso de observação, escuta e interação, independentemente da escala do ambiente observado, visto que a etnografia pode ser realizada em uma sala de aula, em uma escola, em pequenos 
grupos ou em escalas maiores e em ambientes diversificados (OLIVEIRA, 2013; MERCADO MALDONADO, 2019).

\section{Um estudo multissituado em rede}

A configuração do CIERS-ed oferece uma característica particular ao estudo multissituado, visto que não é desenvolvido por um único pesquisador em distintos contextos, mas por uma rede de investigadores em variados ambientes escolares, em colégios públicos e particulares, de zonas rurais e urbanas, em cidades pequenas ou em capitais e regiões metropolitanas.

A elaboração de um documento que norteasse o nosso olhar para as questões de pesquisa identificadas e consensuadas pelos grupos associados ao Centro foi a estratégia encontrada para a realização do projeto de forma a permitir a busca de convergências e a identificação de especificidades da constelação de representações sociais que orientam as práticas docentes.

A elaboração de um protocolo pode parecer um contrassenso à proposta de adotar uma perspectiva etnográfica, sobretudo se encarado como um receituário de procedimentos em campo e guia da observação de aulas. O intuito ao elaborá-lo, no entanto, foi o de estabelecer alguns parâmetros básicos para a pesquisa. Se entendido como objetivo máximo do que se pretende alcançar em campo, configura-se como limitante das possibilidades de pesquisa. No entanto, tomado como ponto de partida e não de chegada, ele se torna um elemento articulador de experiências diversas.

Ao considerarmos que o delineamento de uma pesquisa de natureza multicêntrica deve garantir a produção de informações a partir de uma base metodológica comum que permita, além de análises circunscritas aos interesses de cada pesquisador ou grupo de pesquisa envolvido no projeto, sistematizações e interpretações mais abrangentes, incluindo corpora de análise mais extensos e de diversas procedências, adotamos duas estratégias: (a) a organização de um protocolo de pesquisa com cinco orientações relativas aos procedimentos metodológicos de produção de informação; (b) a compilação das informações produzidas em um banco sistematizado na Fundação Carlos Chagas. 
O protocolo é composto por um conjunto de quatro instrumentos (Roteiro de Contextualização, Roteiro de Observação de Aula, Carta do(a) Docente e Conversa entre Estudantes) e uma carta para o(a) diretor(a) da escola onde a pesquisa será desenvolvida. Elaboramos os instrumentos visando a compreensão de representações de educadores e educandos sobre: ser professor e ser aluno; prática docente e prática discente, bem como sobre o contexto escolar.

A observação das interações educacionais no contexto das escolas públicas de ensino fundamental e o registro de material discursivo na forma de narrativas de educadores e educandos compõem o documento norteador do campo, que foi elaborado sob a premissa de que as práticas docentes são fenômenos orientados por representações sociais, expressões de representações, mas também produtoras de representações.

O roteiro de contextualização corresponde à primeira etapa do trabalho de campo e tem por objetivo conhecer o processo de constituição da escola, sua organização e seu contexto sociocultural, assim como levantar informações iniciais sobre o professor colaborador (regente da classe onde ocorre a observação). As informações obtidas nesta etapa visam permitir aos pesquisadores que estão em campo, assim como aos pesquisadores que utilizarão o banco de dados do CIERS-ed, construir as análises de forma contextualizada.

O segundo roteiro refere-se à observação de aula e busca favorecer a identificação e a compreensão de processos que constituem a experiência escolar cotidiana, visto que:

Por meio de técnicas etnográficas de observação participante e de entrevistas intensivas, é possível documentar o não documentado, isto é, desvelar os encontros e desencontros que permeiam o dia a dia da prática escolar, descrever as ações e representações de seus atores sociais, reconstruir sua linguagem, suas formas de comunicação e os significados que são criados e recriados no cotidiano do seu fazer pedagógico (ANDRÉ, 2007, p. 41).

Com o propósito de identificar convergências nas informações produzidas pela pesquisa, o que ampliará as chances de uma generalização analítica, definimos alguns critérios para a seleção das escolas, turmas e disciplinas, sendo esses: a) escolas de ensino fundamental da rede pública municipal ou estadual, b) turmas de sétimo ou oitavo ano e c) aulas das disciplinas do eixo de ciências humanas (geografia ou 
história). Foi também consensuado com os grupos de pesquisa associados ao CIERSed um número mínimo de observação de cinco aulas (além das demais visitas de contextualização previstas no protocolo), de preferência em aulas subsequentes.

O roteiro de observação de aula inclui orientações que abrangem várias etapas do processo de construção do relato etnográfico: descrição do contexto geral em que ocorreu a observação, relato detalhado da observação, informações complementares obtidas após a observação, autorreflexão do pesquisador sobre a sua atuação durante a observação, reflexões iniciais e antecipações de sentidos sobre o observado e orientações sobre a configuração final do relatório de observação a ser enviado para o CIERS-ed.

O terceiro instrumento propõe a construção de uma narrativa por parte do(a) docente colaborador(a) sobre a sua atividade profissional cotidiana e é composto por: orientações para a produção de uma carta a um(a) colega docente, forma de digitação por parte do(a) pesquisador(a) e envio para o CIERS-ed. A elaboração deste instrumento se articulou com outro projeto em rede abrigado pelo Centro "El quehacer docente: intercambio de narrativas entre docentes latino-americanos" ${ }^{4}$ e previu a escrita de uma carta a partir da seguinte consigna:

\section{"Prezado(a) colega,}

Meu nome é Eli, dou aula há seis anos em uma escola de minha cidade, mas por questões familiares vou me mudar para a sua cidade. Fiquei sabendo que na escola em que você trabalha há vagas para o processo de remoção no próximo ano. Esta não é uma decisão fácil, por isso, gostaria de lhe pedir um favor, você poderia me contar um pouco sobre como é trabalhar nessa escola? Como é dar aula aí? Como é o ensino? Como são os alunos, os colegas e a gestão? Enfim, como é o seu dia a dia?

Desde já agradeço sua atenção.

Um abraço,

Eli"

\footnotetext{
${ }^{4}$ O Projeto faz parte de um estudo mais amplo "Ben estar e malestar en torno del trabajo docente: aportes para la construcción y validación de um instrumento destinado a su medición", desenvolvido sob a coordenação geral de María Paula Carreras e Cynthia María Torres Stöckl (Universidad Nacional de Tucuman - Argentina). Com o objetivo de investigar o campo experiencial de docentes latinoamericanos para descrever e interpretar o trabalho docente, o estudo promove a troca de cartas entre professores da Argentina, do Brasil, do Uruguai e do México, bem como grupos dialógicos para o debate acerca da experiência docente.
} 
Esperamos que, ao responder essa carta, o(a) docente produza um relato sobre o seu cotidiano profissional que ofereça elementos sobre as representações que ele tem: a) de si enquanto professor, b) das suas práticas, c) dos estudantes e d) do seu contexto de trabalho.

O quarto e último instrumento, intitulado "Conversa entre estudantes", foi elaborado com o objetivo de promover a construção de narrativas de estudantes que permitam o estudo das representações sociais sobre: a) ser estudante, b) as práticas discentes, c) os(as) docentes e d) o contexto escolar. Para sua elaboração, tomamos como referência protocolos desenvolvidos em estudos anteriores (PASSEGGI; NASCIMENTO; OLIVEIRA, 2016), que utilizaram dispositivos de mediação para desenvolver instrumentos de pesquisa adequados à faixa etária dos respondentes e seu universo cultural.

Para o protocolo em tela, optamos pela simulação de uma conversa entre estudantes do ensino fundamental II sobre as pessoas e as atividades do seu cotidiano escolar. Criamos um formulário com perguntas e espaços para respostas dispostos em balões seguindo o layout do aplicativo WhatsApp ${ }^{\circledR}$. O formulário foi testado com jovens da mesma idade do público-alvo dessa pesquisa, o que possibilitou ajustes de forma, conteúdo e linguagem. O seu preenchimento tem sido realizado em sala de aula, por grupos de quatro ou cinco estudantes. Esperamos que o resultado dessa atividade seja uma narrativa sobre a experiência escolar construída coletivamente.

Faz parte do protocolo um quinto elemento que é a carta de apresentação do projeto para o(a) diretor(a) da escola, acompanhada do termo de manifestação do(a) responsável pelo local onde a pesquisa será desenvolvida. A assinatura do termo pelo diretor habilita o projeto local a ser incorporado ao projeto-mãe ${ }^{5}$ na Plataforma Brasil e sua avaliação pelo Comitê de Ética em Pesquisa.

Quando o instrumento foi apresentado e debatido em reunião técnica com os pesquisadores associados ao CIERS-ed, acordamos o compromisso com o cumprimento das orientações metodológicas e éticas constantes do protocolo. $\mathrm{Na}$

\footnotetext{
${ }^{5}$ Projeto aprovado pelo Comité de Ética em Pesquisa da Universidade Cidade de São Paulo Parecer 3.706.729. 
mesma ocasião destacamos a importância do uso do protocolo com a plasticidade necessária para não inibir o processo de construção inerente ao diálogo com as especificidades do campo.

\section{A pretensão que nos motiva: generalização analítica}

Com base em Marková (2017), consideramos que, apesar de se tratar de uma pesquisa multicêntrica, estamos desenvolvendo um estudo de caso e, como tal, não é passível de generalização por estatística. Por outro lado, se conceitualmente fundamentado e planejado, nosso estudo pode reunir os elementos necessários à generalização analítica, em outros termos, generalização com base em teoria ${ }^{6}$.

Tendo em vista as caraterísticas do CIERS-ed, em especial sua amplitude geográfica (dada a participação de diversos grupos de pesquisa trabalhando articuladamente), o intercâmbio e a discussão dos materiais têm potencializado o processo reflexivo sobre a pesquisa, possibilitando confrontar as interpretações e aumentar a vigilância sobre vieses que poderiam comprometer o trabalho.

Nesse sentido, Pereira (2016) menciona que, entre as contribuições de uma etnografia multissituada, está a possibilidade de perceber peculiaridades de determinados ambientes escolares e também a de identificar regularidades e variações de práticas educativas. Foi assumindo essa orientação que elaboramos o protocolo da pesquisa. Em sua construção, buscamos respeitar os princípios e procedimentos do método etnográfico fundamentados no exercício da alteridade, bem como o caráter interpretativo dos relatos produzidos e a dimensão intersubjetiva das experiências dos envolvidos na pesquisa.

Com amparo na teoria das representações sociais, apostamos na possibilidade de produzir generalização analítica a partir do estudo das convergências e especificidades do material reunido por todos os grupos.

\footnotetext{
${ }^{6}$ Nas palavras da autora: "Pode-se sugerir que a generalização teórica, mostrando 'uma posição axiomática clara' em um caso específico, seja susceptível de ter implicações para outros estudos baseados no mesmo posicionamento axiomático, mas realizados em contextos diferentes" (MARKOVÁ, 2017, p. 269).
} 


\section{Referências}

ANDRADE, D.; TEIBEL, É.; ASSUNÇÃO, A. Análise sociogenética do núcleo central das representações sociais: investigações sobre o cuidado hospitalar de crianças. Revista de Educação Pública, v. 29, jan./dez. 2020. doi: https://doi.org/10.29286/rep.v29ijan/dez.10294

ANDRÉ, M. E. D. A. Etnografia da prática escolar. 13. ed. Campinas: Papirus, 2007.

FLORES PALÁCIOS, F. Vulnerabilidad y representación social de género en mujeres de una comunidad migrante. Peninsula, Mérida, v. 9, n. 2, p. 41-58, dic. 2014. Disponível em: http://www.scielo.org.mx/scielo.php?script=sci_arttext\&pid=S187057662014000200002\&lng=es\&nrm=iso. Acesso em: 10 jun. 2020.

FURLANETTO, E. C. Tomar a palavra: uma possibilidade de formação. Revista@mbienteeducação, v. 2, n. 2, p. 128-135, mar. 2018. Disponível em: http://publicacoes.unicid.edu.br/index.php/ambienteeducacao/article/view/559. Acesso em: 10 jun. 2020.

JODELET, D. Loucuras e representações sociais. Petrópolis: Vozes, 2005.

JOVCHELOVITCH, S. Os contextos do saber: representações comunidade e cultura. Trad. Pedrinho Guareschi. 2. ed. Petrópolis: Vozes, 2011. 344p.

MALINOWSKI, B. Argonautas do pacífico ocidental. Introdução: objeto e âmbito desta investigação. In: CASTRO C. (Org.) Textos Básicos de Antropologia. Rio de Janeiro: Zahar, 2016a.

MALINOWSKI, B. Confissões de ignorância e fracasso. In: CASTRO C. (Org.) Textos Básicos de Antropologia. Rio de Janeiro: Zahar, 2016b.

MARKOVÁ, I. Mente dialógica: senso comum e ética. Trad. Lilian Ulup. Cambridge: Cambridge University Press; São Paulo: Fundação Carlos Chagas; Curitiba: PUCPRESS, 2017.

MERCADO MALDONADO, R. Saberes Docentes como construcción social: la enseñanza centrada en los niños. México: Fondo de Cultura Económica, 2002.

MERCADO MALDONADO, R. Curso Etnografia da Docência cotidiana, Fundação Carlos Chagas, São Paulo 8 e 9 de maio de 2019. Notas de aula.

NOVAES, A.; PASSEGGI, M. Fita de Möbius e fractal: aproximações entre representações sociais e narrativas. Revista de Educação Pública, v. 29, jan./dez. 2020. doi: https://doi.org/10.29286/rep.v29ijan/dez.10127

NOVAES, A.; SOUSA, C. P. ; VILLAS BÔAS, L. S. O balanço das produções do CIERSed: avanços e identificação de novas hipóteses. In: NOVAES, A.; SOUSA, C. P. ; VILLAS BÔAS, L. S. (Org.). Sistematizações e proposições para o campo da educação e das representações sociais. 1. ed. Curitiba: CRV, 2019. 254p .

OLIVEIRA, A. Algumas pistas (e armadilhas) na utilização da Etnografia na Educação. Revista Educação em Foco, Juiz de Fora, ano 16, n. 22, p. 163-183, 2013. 
PASSEGGI, M.; NASCIMENTO, G.; OLIVEIRA, R. As narrativas autobiográficas como fonte e método de pesquisa qualitativa em educação. Revista Lusófona de Educação, n. 33, p. 111-125, jul. 2016.

PEREIRA, A. B. Outros ritmos em escolas da periferia de São Paulo. Educação e Realidade, Porto Alegre, v. 41, n. 1, jan./mar. 2016.

SEIDMANN, S. Narrativas y representaciones sociales: inspirada en y dialogando con Sandra Jovchelovitch. Revista de Educaşão Pública, v. 29, jan./dez. 2020. doi: https://doi.org/10.29286/rep.v29ijan/dez.10045.

SERRANO OSWALD, S. E. El potencial de la teoría de representaciones sociales (TRS) para la investigación con perspectiva de equidad de género. Acta Colombiana de Psicologia, Bogotá, v. 16, n. 2, p. 63-70, Dec. 2013. Disponível em: http://www.scielo.org.co/scielo.php?script=sci_arttext\&pid=S0123-91552013000200006\&lng=en\&nrm=iso. Acesso em: 10 jun. 2020.

VELHO, G. Observando o Familiar. In: NUNES, E. N. A Aventura Sociológica. Rio de Janeiro: Zahar, 1978.

RECEBIDO: $19 / 06 / 2020$

APROVADO: 08/07/2020

RECEIVED: 06/19/2020

APPROVED: 07/08/2020

RECIBIDO: $19 / 06 / 2020$

APROBADO: 08/07/2020 